ЭКОЛОГО-ГЕОХИМИЧЕСКАЯ ОЦЕНКА ТЕРРИТОРИИ ПОД СТРОИТЕЛЬСТВО АЗОВСКОГО ЗЕРНОВОГО ТЕРМИНАЛА

\author{
Шишкина Д.Ю., Баумара М.А., Латун В.В. \\ ФГАОУ ВО «Южный федеральный университет», Ростов-на-Дону, е-mail: diana@sfedu.ru
}

\begin{abstract}
Ростовская область вносит большой вклад в экспорт российского зерна. По итогам 2020/2021 сельскохозяйственного года область стала лидером экспорта зерна из России благодаря развитой инфраструктуре морских портов Ростов, Азов и Таганрог. Строительство портовых сооружений ведет к росту антропогенной нагрузки на ландшафты Нижнего Дона, поэтому изучение экологического состояния территории до начала застройки является актуальной задачей. Статья основана на материалах, полученных в ходе инженерно-экологических изысканий на участке под строительство зернового терминала в Азовском морском порту. Изыскания проводились в 2019-2020 годах на территории площадью 3 га и участке акватории площадью 4 га. Изучались химический состав и уровень загрязнения атмосферного воздуха, поверхностных и подземных вод, почв, донных отложений. Установлен высокий уровень загрязнения атмосферного воздуха, обусловленный повышенными концентрациями взвешенных веществ, оксида углерода, диоксида и оксида азота, бенз(а)пирена и формальдегида. Для воды реки Дон характерны повышенные по сравнению с нормативами качества воды для рыбохозяйственных водоемов содержания сульфатов, нитритов, фосфатов, фенолов, нефтепродуктов и комплекса тяжелых металлов. Почвы отличаются пониженными, относительно регионального геохимического фона, содержаниями тяжелых металлов и мышьяка, что связано с низким содержанием гумуса и глинистых частиц. Содержание бенз(а)пирена и нефтепродуктов в почве не превышает предельно допустимых концентраций, в то же время выявлено загрязнение хлорорганическими инсектицидами и полихлорированными бифенилами. Донные отложения по микроэлементному составу близки к почвам, загрязнение органическими веществами отсутствует. Эколого-геохимическая ситуация оценена как напряжённая.
\end{abstract}

Ключевые слова: зерновой терминал, река Дон, Ростовская область, загрязнение, тяжелые металлы

\title{
ECOLOGICAL AND GEOCHEMICAL ASSESSMENT OF THE TERRITORY FOR CONSTRUCTION OF THE AZOV GRAIN TERMINAL
}

\author{
Shishkina D.Y., Baumara M.A., Latun V.V. \\ Southern Federal University, Rostov-on-Don, e-mail: diana@sfedu.ru
}

\begin{abstract}
The Rostov region makes a great contribution to the export of Russian grain. At the end of the 2020/2021 agricultural year, the region became the leader in grain exports from Russia thanks to the developed infrastructure of the seaports of Rostov, Azov and Taganrog. The construction of port facilities leads to an increase in the anthropogenic load on the landscapes of the Lower Don, therefore, the study of the ecological state of the territory before the start of development is an urgent task. The article is based on materials obtained in the course of engineering and environmental surveys at the site for the construction of a grain terminal in the Azov seaport. The surveys were carried out in 2019-2020 on an area of 3 hectares and a section of water area of 4 hectares. The chemical composition and level of pollution of atmospheric air, surface and ground waters, soils, bottom sediments were studied. A high level of atmospheric air pollution was established, due to increased concentrations of suspended solids, carbon monoxide, dioxide and nitrogen oxide, benzo (a) pyrene and formaldehyde. The water of the Don River is characterized by an increased content of sulfates, nitrites, phosphates, phenols, petroleum products and a complex of heavy metals in comparison with the water quality standards for fishery reservoirs. The soils are characterized by low contents of heavy metals and arsenic relative to the regional geochemical background, which is associated with a low content of humus and clay particles. The content of benzo (a) pyrene and petroleum products in the soil does not exceed the maximum permissible concentrations, at the same time, pollution with organochlorine insecticides and polychlorinated biphenyls has been revealed. In terms of trace element composition, bottom sediments are close to soils, there is no organic pollution. The ecological and geochemical situation was assessed as tense.
\end{abstract}

Keywords: grain terminal, Don river, Rostov region, pollution, heavy metals

Ростовская область имеет выгодное расположение с точки зрения возможностей развития водного транспорта, прежде всего за счет реки Дон, проходящей через всю территорию области и соединенной Волго-Донским каналом с другими речными артериями России. По Дону осуществляется выход судов в Азовское, Черное моря и далее в международные воды. Все три круглогодичных морских порта (Азовский, Ростовский и Таганрогский) являются универсальными, при этом основными грузами выступают зерно и уголь. В рам- ках нацпроекта «Международная кооперация и экспорт» перед Ростовской областью поставлена задача довести объем агроэкспорта до 5,4 млрд долларов. С этой целью в донском регионе продолжается развитие экспортоориентированной логистической инфраструктуры, в частности реализуется четыре инвестпроекта, направленных на увеличение пропускной способности терминалов в портах Азова и Таганрога не менее чем на 13 млн тонн [1].

Интенсивное развитие портовой инфраструктуры, рост грузооборота Ростовского 
и Азовского портов, строительство Багаевского гидроузла увеличивают и без того мощную антропогенную нагрузку на геосистемы дельты Дона. В этих условиях возрастает актуальность исследований, направленных на изучение экологического состояния наземных и аквальных ландшафтов, ещё не подвергшихся антропогенному преобразованию.

Целью исследования является комплексная эколого-геохимическая оценка территории и акватории под строительство зернового терминала в морском порту Азов.

\section{Материалы и методы исследования}

В основу статьи положены результаты инженерно-экологических изысканий (ИЭИ), проведенных в 2019-2020 гг. на участке под строительство зернового терминала в Азовском морском порту на левом берегу р. Дон. Карта-схема района размещения проектируемого объекта приведена на рисунке. Изыскания выполнялись на территории площадью 3 га и на примыкающем участке акватории искусственного залива (ковша) площадью 4 га. Участок с за- пада, юга и востока окружен действующими и строящимися портовыми причалами морского порта Азов.

На территорию проектируемого зернового терминала распространяется ряд экологических ограничений. Участок расположен в границах водоохранной зоны и прибрежной защитной полосы р. Дон рыбохозяйственного объекта высшей категории. Кроме того, он находится во втором поясе зоны санитарной охраны (ЗСО) водозаборных сооружений МП «Азовводоканал» и входит в третий пояс $3 \mathrm{CO}$ водозаборных сооружений в районе х. Дугино - источника водоснабжения населения г. Ростова-на-Дону.

В рамках ИЭИ проведены эколого-геохимические и агрохимические исследования, изучен химический состав почв, донных отложений, природных вод, атмосферного воздуха и выявлены наличие и уровень загрязнения этих компонентов окружающей среды. В ходе изысканий было отобрано 10 проб почвы, 8 - донных отложений, 2 пробы подземных вод и 2 пробы воды из р. Дон.

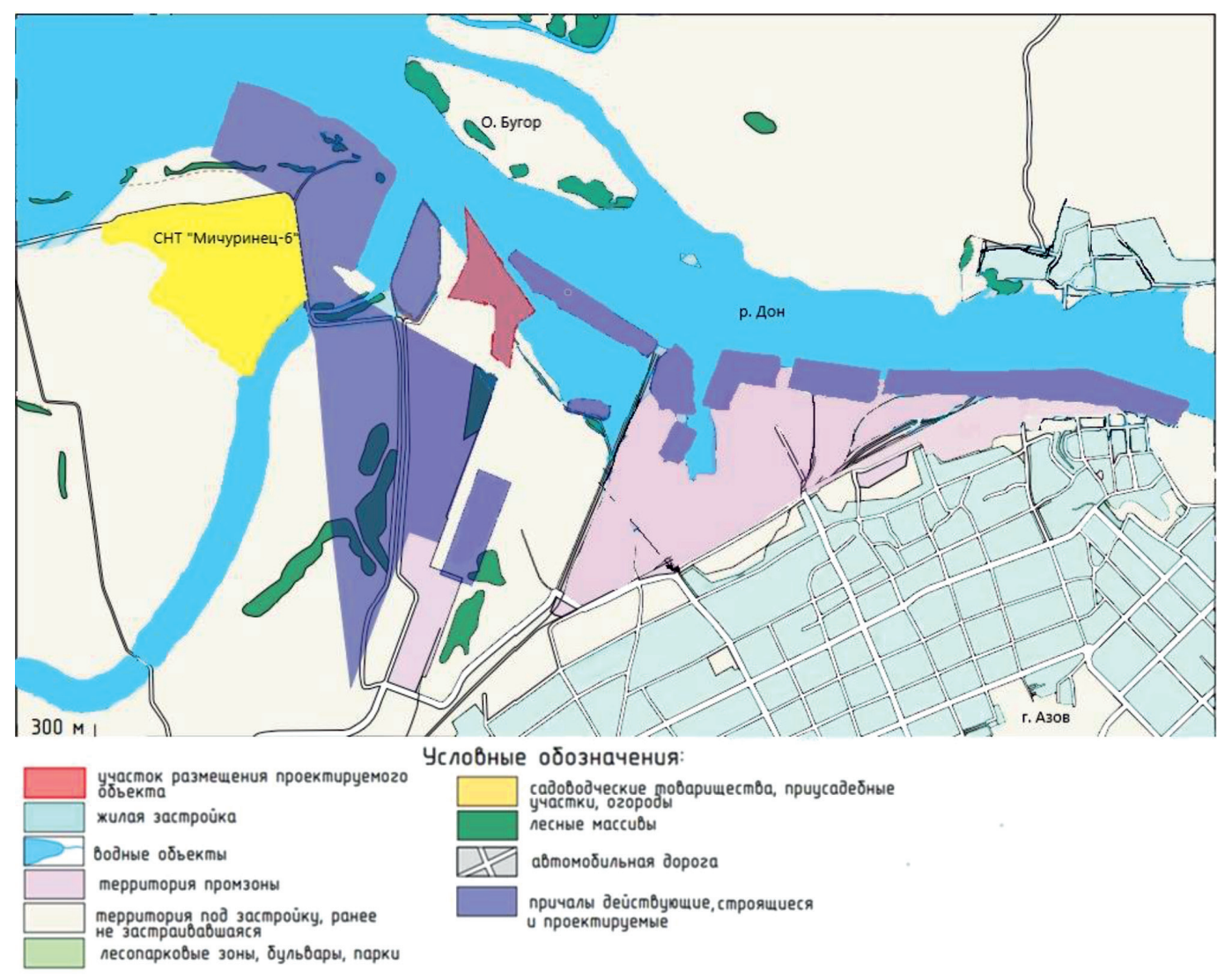

Карта-схема района размещчения проектируемого Азовского зернового терминала 
Содержание загрязняющих веществ в атмосферном воздухе, мг/ ${ }^{3}$

\begin{tabular}{|c|c|c|c|c|c|c|}
\hline \multirow{2}{*}{$\begin{array}{c}\text { Загрязняющие } \\
\text { вещества }\end{array}$} & \multirow{2}{*}{$\begin{array}{l}\text { Площадка } \\
\text { изысканий }\end{array}$} & \multicolumn{2}{|c|}{ г. Азов [2] } & \multirow[t]{2}{*}{ ПДКс.с. [3] } & \multirow[t]{2}{*}{ ПДКм.р. [3] } & \multirow{2}{*}{$\begin{array}{c}\text { Класс } \\
\text { опасности }\end{array}$} \\
\hline & & 2019 г. & 2020 г. & & & \\
\hline Взвешенные вещества & 0,4 & 0,2 & 0,3 & 0,15 & 0,5 & 3 \\
\hline Диоксид серы & 0,009 & 0,004 & 0,007 & 0,05 & 0,5 & 3 \\
\hline Оксид углерода & 4,0 & 1,6 & 1,5 & 3,0 & 5,0 & 4 \\
\hline Диоксид азота & 0,19 & 0,03 & 0,03 & 0,1 & 0,2 & 3 \\
\hline Оксид азота & 0,15 & 0,02 & 0,039 & - & 0,4 & 3 \\
\hline Бенз(а)пирен, нг/M³ & 1,57 & 0,4 & 0,6 & 1,0 & - & 1 \\
\hline Формальдегид & 0,024 & 0,007 & 0,008 & 0,01 & 0,05 & 2 \\
\hline
\end{tabular}

Для изучения состояния атмосферного воздуха использовались данные, предоставленные Северо-Кавказским управлением по гидрометеорологии и мониторингу окружающей среды, а также материалы Государственного доклада «О состоянии окружающей среды и природных ресурсов Ростовской области» [2]. В пробах воды определялись общие показатели качества вод (сухой остаток, общая жесткость, водородный показатель и др.), концентрации главных ионов, а также содержания биогенных веществ и основных загрязняющих веществ.

В пределах площадки изысканий изучалось распределение в почвах и донных отложениях химических элементов и соединений, являющихся приоритетными токсикантами окружающей среды: тяжелых металлов, мышьяка, нефтепродуктов и бенз(а) пирена, а также удельная активность природных и техногенных радионуклидов. Дополнительно исследовались показатели, определяемые для зон санитарной охраны водоемов [3].

Тяжелые металлы в пробах почв и донных отложений анализировались методами атомно-эмиссионной и атомно-абсорбционной спектрометрии. Для определения содержаний нефтепродуктов использовался флуориметрический метод, цианидов - фотометрический метод, полихлорбифенилов и галогенорганических пестицидов - газожидкостная хроматография, бенз(а)пирена - жидкостная хроматография. Анализы выполнялись в ФГБУ ГЦАС «Ростовский» и АНО «Испытательный центр «НОРТЕСТ».

\section{Результаты исследований и их обсуждение}

Фоновые концентрации загрязняющих веществ в атмосферном воздухе, кроме диоксида серы, выше среднесуточных ПДК
(ПДКс.с. ) (табл. 1). Кратность превышения ПДК веществ третьего и четвёртого классов опасности варьирует от 1,3 (оксид углерода) до 2,7 (взвешенные вещества). Для оксида азота ПДКс.с. не установлена, но сравнение со среднегодовой ПДК $\left(0,06 \mathrm{мг} / \mathrm{M}^{3}\right)$ показывает превышение этого норматива в 2,5 раза. Содержания веществ первого и второго классов опасности - бенз(а)пирена и формальдегида - превосходят среднесуточную ПДК в 1,57 и 2,4 раза. Максимальные разовые ПДК (ПДКм.р.) не превышены ни по одному веществу.

Рассчитанный индекс загрязнения атмосферы $\left(\right.$ ИЗА $\left._{5}\right)$ составляет 9,5, что определяет уровень загрязнения атмосферного воздуха как высокий. Причиной высокого уровня загрязнения атмосферного воздуха является интенсивная антропогенная нагрузка на территорию порта, где проводятся погрузочно-разгрузочные работы с пылящими грузами (каменный уголь, зерно и др.) и работает транспорт. Загрязнение атмосферного воздуха в пределах Азовского морского порта носит стабильный характер, причём основной вклад в его формирование вносят зерновая и угольная пыль, суммарное поступление которых в атмосферу превышает 120 т/год [4]. Концентрации загрязняющих веществ в атмосферном воздухе на территории г. Азов, наблюдаемые в последние годы, заметно ниже по сравнению с территорией морского порта. Лишь содержания взвешенных веществ превышают в 1,3-2 раза среднесуточные ПДК.

В пробах воды р. Дон и грунтовых вод определялся широкий комплекс гидрохимических показателей и концентраций химических элементов и веществ (табл. 2). При экологической оценке принимался во внимание комплексный характер использования р. Дон - как источника хозяйственно- 
питьевого водоснабжения, а также водного объекта рыбохозяйственного значения высшей категории, поэтому экологическое состояние оценивалось на основе требований, предъявляемых как к воде подземных и поверхностных водных объектов хозяйственно-питьевого и культурно-бытового водопользования, так и к воде водных объектов рыбохозяйственного значения [3; 5]. При этом, исходя из требований п. 14 Постановления Правительства Российской Федерации от 13 февраля 2019 г. № 149, нормативы качества принимались на уровне наименьшего из гигиенического или рыбохозяйственного нормативов.

По сравнению с рыбохозяйственными нормативами в донской воде повышены величины БПК фатов, нитритов, фосфатов, фенолов нефтепродуктов, меди, никеля, свинца и марганца. Самое высокое превышение ПДК отмечается по фенолам - в 63 раза. Содержание растворённого кислорода в 10 раз ниже нормы. Гидрохимический состав проб из акватории проектируемого терминала в целом близок к составу донской воды, установленному в результате многолетних наблюдений и ежегодного мониторинга [2; 6]. Изменчивость гидрохимического состава обусловлена разным временем отбора проб, соответствующим различным фазам гидрологического цикла.

В грунтовых водах по сравнению c нормативами хозяйственно-питьевого водоснабжения постоянно превышены показатели ХПК; в отдельные сезоны - минерализация, содержание фенолов и нефтепродуктов. В целом гидрохимический состав поверхностных и подземных вод весьма близок, поскольку грунтовые воды, приуроченные к аллювиальным отложениям, имеют тесную связь с р. Дон. Следует подчеркнуть, что небольшая глубина залегания грунтовых вод и отсутствие вышезалегающего водоупорного горизонта обусловили крайне низкую степень их защищенности от проникающих с поверхности загрязнений.

Таблица 2

Гидрохимические показатели и содержание химических веществ в воде, мг/дм

\begin{tabular}{|c|c|c|c|c|}
\hline Показатели, ед. измерения & $\begin{array}{l}\text { Вода } \\
\text { p. Дон }\end{array}$ & $\begin{array}{c}\text { Подземные } \\
\text { воды }\end{array}$ & $\begin{array}{c}\text { Показатели качества } \\
\text { и ПДК химических } \\
\text { веществ [3] }\end{array}$ & $\begin{array}{c}\text { Нормативы } \\
\text { качества } \\
\text { и ПДК } \\
\text { вр }[4]\end{array}$ \\
\hline Водородный показатель, ед. pH & $7,62-8,2$ & $7,71-8,03$ & $6-9$ & - \\
\hline Сухой остаток & $612-856$ & $328-1192$ & 1000 & - \\
\hline Общая жёсткость, мг-экв/дм³ & 6,18 & $2,6-8,73$ & 7 & - \\
\hline Растворённый кислород & $0,4-8,34$ & $6,49-9,41$ & не менее 4,0 & не менее 4,0 \\
\hline Взвешенные вещества & $0,09-4,8$ & $12-43$ & не более + 0,75 к фону & - \\
\hline $\mathrm{XПК,} \mathrm{M \Gamma O}_{2} /$ дм $^{3}$ & $28,4-60$ & $77-139$ & 30,0 & - \\
\hline БПК ${ }_{5}, \mathrm{M \Gamma O}_{2} /$ дм$^{3}$ & $2,6-2,84$ & 2,88 & 4,0 & 2,1 \\
\hline Сульфаты & $183-200$ & $8,26-307$ & 500 & 100 \\
\hline Хлориды & $79,4-135$ & $19,3-135$ & 350 & 300 \\
\hline Нитраты & $0,64-2,1$ & 3,4 & 45 & 40 \\
\hline Нитриты & 0,099 & $0,12-0,28$ & 3,0 & 0,08 \\
\hline Аммоний-ион & 0,13 & $0,29-0,53$ & 1,5 & 0,4 \\
\hline Фосфаты & 0,54 & 3,01 & 3,5 & 0,15 \\
\hline Железо & 0,076 & $0,11-0,14$ & 0,3 & 0,1 \\
\hline Марганец & $0,0103-0,043$ & 0,013 & 0,1 & 0,01 \\
\hline Медь & 0,0032 & $0,04-0,0044$ & 1,0 & 0,001 \\
\hline Никель & $0,012-0,0152$ & 0,0075 & 0,02 & 0,01 \\
\hline Свинец & $0,0025-0,0073$ & 0,0002 & 0,01 & 0,006 \\
\hline Цинк & $0,0076-0,043$ & $0,011-0,017$ & 5,0 & 0,01 \\
\hline Кремний & 4,49 & $1,16-3,12$ & 20 & - \\
\hline Нефтепродукты & $0,018-0,16$ & $0,054-0,49$ & 0,1 & 0,05 \\
\hline Фенолы & $0,0006-0,063$ & $0,0073-0,16$ & 0,1 & 0,001 \\
\hline
\end{tabular}


Содержание химических элементов в верхнем почвенном горизонте на площадке изысканий, мг/кг

\begin{tabular}{|l|c|c|c|c|c|}
\hline $\begin{array}{c}\text { Химические } \\
\text { элементы }\end{array}$ & $\begin{array}{c}\text { Пределы колеба- } \\
\text { ний содержаний }\end{array}$ & $\begin{array}{c}\text { Среднее } \\
\text { содержание }\end{array}$ & $\begin{array}{c}\text { Региональный гео- } \\
\text { химический фон [7] }\end{array}$ & $\begin{array}{c}\text { Местный геохи- } \\
\text { мический фон }\end{array}$ & $\begin{array}{c}\text { ПДК, ОДК для } \\
\text { песчаных и су- } \\
\text { песчаных почв [3] }\end{array}$ \\
\hline Свинец & $1,03-2,87$ & 2,19 & 24 & 18 & 32 \\
\hline Цинк & $3,32-12,5$ & 9,02 & 84,3 & 57 & 55 \\
\hline Кадмий & 0,05 & 0,05 & 0,22 & 0,16 & 0,5 \\
\hline Ртуть & 0,005 & 0,005 & 0,018 & 0,011 & 2,1 \\
\hline Мышьяк & $0,39-0,9$ & 0,61 & 4,76 & 3,3 & 2 \\
\hline Никель & $7,67-12,2$ & 10,7 & 41 & 33 & 20 \\
\hline Медь & $2,4-5,35$ & 4,4 & 34,8 & 27 & 33 \\
\hline
\end{tabular}

На участке изысканий развиты аллювиальные примитивные и слоистые почвы супесчаного состава (содержание физической глины 13,09-14,22\%). Исследуемые почвы имеют слабощелочную реакцию среды $(\mathrm{pH}=8,0-8,5)$ и низкое содержание гумуса - 0,52-0,75\%. Поглотительная способность варьирует от средней (ЕКО 18,4 мг-экв/100 г) до выше средней (ЕКО 34,2 мг-экв/100 г).

Распределение тяжёлых металлов и металлоидов (ТММ) в почвенном покрове довольно равномерное. Характерной особенностью является низкое, по сравнению c зональными чернозёмами, содержание всех химических элементов, обусловленное гранулометрическим составом почвообразующих пород - аллювиальных преимущественно кварцевых песков, резко обеднённых ТММ. Кларки рассеяния по отношению к региональному фону - североприазовским чернозёмам ООПТ «Персиановская степь»варьируют от 3,8 (никель) до 11 (свинец). В качестве местного геохимического фона использовались результаты анализа почвенной пробы, отобранной в сходных ландшафтно-геохимических условиях за восточной окраиной Азова. Очевидно, что по сравнению с местным фоном почвы площадки изысканий также обеднены тяжёлыми металлами и мышьяком (табл. 3).

В основном концентрации элементов на один-два порядка меньше ОДК для песчаных и супесчаных почв, исключая никель, концентрации которого сопоставимы с санитарно-гигиеническим нормативом, и ртуть, ПДК которой на три порядка превосходит установленные нами концентрации.

Низкие содержания ТММ в супесчаных и песчаных аллювиально-луговых и аллювиально-слоистых почвах донской дельты, отмеченные многими исследователями, обусловлены слабой гумусированностью почв, низким содержанием поглощенных катионов и илистых частиц [8]. Концентрации химических элементов в донных отложениях сопоставимы с таковыми в почвах. Так, средние содержания $\mathrm{Pb}$ составляют 2,36, Cu - 4,09, Zn - 11,24 мг/кг. Микроэлементный состав донных отложений акватории ковша в целом соответствует известным данным по геохимии песчаной фракции осадков русла Дона [9].

Нефтепродукты в пробах почвы и донных осадков обнаружены в концентрациях от 5 до 15 мг/кг. В настоящее время отечественная ПДК для нефтепродуктов ещё не разработана, поэтому для приближенной оценки можно воспользоваться величиной 1000 мг/кг, которая рекомендуется в качестве рубежа между допустимым и низким уровнем загрязнения [10]. Содержания бенз(а)пирена в почве и донных отложениях не достигают 0,005 мг/кг, что также значительно ниже ПДК $(0,02$ мг/кг).

Расположение проектируемого объекта в пределах $3 \mathrm{CO}$ источников водоснабжения диктует необходимость определения ряда показателей оценки санитарного состояния почв населенных пунктов в зонах санитарной охраны водоемов: азота аммонийного и нитратного, хлоридов, фенолов, полихлорированных бифенилов (ПХБ), детергентов и др. Так, содержание аммонийного азота варьировало от 2,29 до 2,71 мг/кг, азота нитратного от 1,68 до 3,36 мг/кг, хлоридов - от 20,2 до 47,2 мг/кг. Концентрации некоторых веществ, например фенолов и цианидов, были ниже предела обнаружения - 0,05 и 0,5 мг/кг соответственно.

Особого внимания заслуживает содержание в почве хлорорганических инсектицидов гексахлорциклогексана (ГХЦГ) и дихлордифенилтрихлорметилметана (ДДТ). Если со- 
держание первого не достигает 0,01 мг/кг при ПДК 0,1 мг/кг, то концентрация второго в одной пробе равна 0,064 , а во второй 0,16 мг/кг, что в 1,6 раза превышает ПДК. Содержание полихлорированных бифенилов (ПХБ) в этой же почвенной пробе составляет 0,22 мг/кг - в 11 раз выше ОДК.

Удельная эффективная активность естественных радионуклидов (Th-232, Ra-226, K-40) в почвах и донных отложениях сравнивалась с нормативом для строительных материалов, используемых для вновь строящихся жилых и общественных зданий. Этот показатель изменяется от 31,81 до 104,24 Бк/ кг, что ниже норматива 370 Бк/кг.

\section{Выводы}

1. Атмосферный воздух выделяется среди остальных компонентов ландшафта самым широким спектром загрязняющих веществ: из семи изученных веществ концентрации шести превышают среднесуточные ПДК. Наиболее высокими концентрациями отличаются оксид азота и взвешенные вещества.

2. В акватории проектируемого терминала наблюдаются повышенные по сравнению с ПДК в воде водных объектов рыбохозяйственного значения величины БПК содержания сульфатов, нитритов, фосфатов, фенолов нефтепродуктов, меди, никеля, свинца и марганца. Наибольшая кратность превышения ПДК установлена для фенолов.

3. Сравнение полученных гидрохимических показателей и концентраций веществ в подземных водах с нормативами хозяйственно-питьевого и культурно-бытового водопользования показало превышение по величине ХПК, минерализации, содержанию фенолов и нефтепродуктов.

4. Почвенно-геохимическая специфика заключается в обеднении ТММ по сравнению с локальным и региональным фоном ввиду лёгкого гранулометрического состава. В то же время почва на площадке изысканий загрязнена органическими экотоксикантами ДДТ и ПХБ.

5. Ввиду высокого уровня загрязнения атмосферного воздуха, присутствия в воде и почве комплекса токсичных элементов и веществ эколого-геохимическая ситуация в пределах площадки изысканий оценивается как напряжённая.

\section{Список литературы / References}

1. В июне значительно вырос экспорт пшеницы из портов Ростовской области. [Электронный ресурc]. URL: http:// www.don-agro.ru/index.php/news/773-v-iyune-znachitelno- vyros-eksport-pshenitsy-iz-portov-rostovskoj-oblasti (дата обращения: 15.11.2021).

In June, wheat exports from the ports of the Rostov region increased significantly. [Electronic resource]. URL: http://www. don-agro.ru/index.php/news/773-v-iyune-znachitelno-vyroseksport-pshenitsy-iz-portov-rostovskoj-oblasti (date of access: 15.11.2021) (in Russian).

2. Экологический вестник Дона «О состоянии окружающей среды и природных ресурсов Ростовской области в 2020 году». [Электронный ресурс]. URL: https://минприродыро.pф/projects/19/ (дата обращения: 30.11.2021).

Ecological Bulletin of the Don «On the state of the environment and natural resources of the Rostov region in 2020». [Electronic resource]. URL: https:/минприродыро.pф/ projects/19/ (date of access: 30.11.2021) (in Russian).

3. Постановление Главного государственного санитарного врача РФ от 28.01.2021 № 2 «Об утверждении санитарных правил и норм СанПиН 1.2.3685-21 «Гигиенические нормативы и требования к обеспечению безопасности и (или) безвредности для человека факторов среды обитания». [Электронный ресурc]. URL: http://www.consultant.ru/ document/cons_doc_LAW_375839/fa69e15a74de57cbe09d347462434c11fcfeeaca/ (дата обращения: 15.11.2021).

Resolution of the Chief State Sanitary Doctor of the Russian Federation dated 28.01.2021 No. 2 «On the approval of sanitary rules and norms SanPiN 1.2.3685-21 «Hygienic standards and requirements for ensuring the safety and (or) harmlessness of environmental factors for humans». [Electronic resource]. URL: http://www.consultant.ru/document/cons doc LAW 375839/fa69e15a74de57cbe09d347462434c11 fcfeeaca/ (date of access: 15.11.2021) (in Russian).

4. Арташесян А.А., Комиссаров К.Б., Филь А.В. Предложение для ОАО «Азовский морской порт» по уменьшению количества выбросов загрязняющих веществ в атмосферу для улучшения экологической обстановки на предприятии и за его пределами // Транспорт. Экономика. Социальная сфера. (Актуальные проблемы и их решения): сборник статей III Международной научно-практической конференции (г. Пенза, 21-22 апреля 2016 г.). Пенза: Пензенский государственный аграрный университет, 2016. С. 8-15.

Artashesyan A.A., Komissarov K.B., Fil' A.V. Proposal for JSC «Azov Sea Port» to reduce the amount of emissions of pollutants into the atmosphere to improve the environmental situation at the enterprise and beyond // Transport. Ekonomika. Social'naya sfera. (Aktual'nye problemy i ih resheniya): sbornik statej III Mezhdunarodnoj nauchno-prakticheskoj konferencii (g. Penza, 21-22 aprelya 2016 g.). Penza: Penzenskij gosudarstvennyj agrarnyj universitet, 2016. P. 8-15 (in Russian).

5. Приказ Министерства сельского хозяйства РФ от 13.12. 2016 г. № 552 «Об утверждении нормативов качества воды водных объектов рыбохозяйственного значения, в том числе нормативов предельно допустимых концентраций вредных веществ в водах водных объектов рыбохозяйственного значения». [Электронный ресурc]. URL: http:// www.consultant.ru/document/cons_doc_LAW_211155/ (дата обращения: 15.11.2021).

Order of the Ministry of Agriculture of the Russian Federation dated 13.12.2016 No. 552 «On approval of water quality standards for fishery water bodies, including standards for maximum permissible concentrations of harmful substances in the waters of fishery water bodies». [Electronic resource]. URL: http://www.consultant.ru/document/cons_doc LAW_211155/(date of access: 15.11.2021) (in Russian).

6. Дельта Дона: эволюция в условиях антропогенной трансформации стока. Ростов-на-Дону: ФГУП «АзНИИРХ», 2009. 184 c.

The Don Delta: evolution in the conditions of anthropogenic transformation of runoff. Rostov-na-Donu: FGUP «AzNIIRH», 2009. 184 p. (in Russian).

7. Шишкина Д.Ю. Тяжелые металлы в почвах Ростована-Дону. Ростов-н/Д.: Издательство ЮФУ, 2017. 98 с.

Shishkina D.Y. Heavy metals in the soils of Rostov-onDon. Rostov-n/D.: Izdatel'stvo YUFU, 2017.98 p. (in Russian).

8. Минкина Т.М., Федоров Ю.А., Невидомская Д.Г., Манджиева С.С., Козлова М.Н. Особенности содержания 
и подвижность тяжелых металлов в почвах поймы реки Дон // Аридные экосистемы. 2016. Т. 22. № 1. С. 86-98.

Minkina T.M., Fedorov Y.A., Nevidomskaya D.G., Mandzhieva S.S., Kozlova M.N. Specific features of content and mobility of heavy metals in soils of floodplain of the Don river // Aridnye ekosistemy. 2016. Vol. 22. № 1. P. 86-98. (in Russian)

9. Хованский А.Д., Латун В.В., Хорошев О.А., Денисов В.И. Оценка воздействия на окружающую среду углубления и расширения судоходных каналов в дельтах рек / Известия высших учебных заведений. Северо-Кавказский регион. Естественные науки. 2018. № 1. C. 104-111. DOI: 10.23683/0321-3005-2018-1-104-111.
Hovanskij A.D., Latun V.V., Horoshev O.A., Denisov V.I. Estimation of environmental impact of deepening and widening of navigable canals in river deltas // Izvestiya vysshih uchebnyh zavedenij. Severo-Kavkazskij region. Estestvennye nauki. 2018. № 1. P. 104-111. DOI: 10.23683/0321-3005-2018-1-104111 (in Russian).

10. Порядок определения размеров ущерба от загрязнения земель химическими элементами. М.: Управление охраны почв и земельных ресурсов Минприроды России, 1993. 31 с.

Procedure for determining the extent of damage from land pollution by chemical elements. M.: Upravlenie ohrany pochv i zemel'nyh resursov Minprirody Rossii, 1993. 31 p. (in Russian). 